\title{
Glucose-6-Phosphate Dehydrogenase (G6pd) Deficiency and Sickle Cell Trait among Blood Donors in Nigeria
}

\author{
Omisakin C.T ${ }^{1, *}$, Esan A.J ${ }^{1}$, Ogunleye A.A ${ }^{2}$, O.Ojo-Bola ${ }^{3}$, Owoseni M.F ${ }^{1}$, Omoniyi D.P ${ }^{1}$ \\ ${ }^{1}$ Haematology and Blood Transfusion Department, Federal Medical Centre, Ido - Ekiti, Nigeria \\ ${ }^{2}$ Ondo State Hospital Management board, Okiti pupa, Nigeria \\ ${ }^{3}$ Medical Microbiology Department, Federal Medical Centre, Ido - Ekiti, Nigeria \\ *Corresponding author: christopheromisakin@gmail.com
}

Received March 04, 2014; Revised March 28, 2014; Accepted March 30, 2014

\begin{abstract}
This study is being aimed to determine the prevalence of glucose-6-phosphate dehydrogenase deficiency and sickle cell trait among blood donors. Blood donation from glucose-6-phosphate dehydrogenase (G6PD)deficient and sickle cell trait (SCT) donors might alter the quality of the donated blood during processing, storage or in the recipient's circulatory system. It has been proposed that several biochemical changes and depletion in the antioxidant defense system occur on storage of G6PD-deficient blood. Red blood cells collected from sickle cell trait donors frequently occlude white blood cells reduction filters; the main cause of this filtration failure is haemoglobin polymerization. A total of 314 blood donor samples were collected from prospective and healthy blood donors after proper screening. Glucose-6-Phosphate dehydrogenase was determined using two standard methods; methaemoglobin reduction test and fluorescent spots test; haemoglobin variants were determined using cellulose acetate electrophoresis at alkaline PH 8.6. Out of the 314 blood donors, 80 (25.5\%) were G6PD deficient, 104 haemoglobin variants AS, AC and SC were 82 (78.8\%), 21 (20.2\%) and 1 (1.0\%) respectively. Commercial blood donors had highest G6PD deficient and highest haemoglobin variants. Age group 25-34 had highest G6PD deficient prevalence while age group 15-24 had highest haemoglobin variants. Transfusion with G6PD-deficient blood carries a potential risk of hemolytic complications, especially if it is used for exchanged blood transfusion in neonates. On the other hand, the blood donated from SCT donors, apart from its undesired effects if transfused to sickle cell disease patients, also leads to WBC filtration failure.
\end{abstract}

Keywords: blood donors, G6PD deficiency, sickle cell trait

Cite This Article: Omisakin C.T, Esan A.J, Ogunleye A.A, O.Ojo-Bola, Owoseni M.F, and Omoniyi D.P, "Glucose-6-Phosphate Dehydrogenase (G6pd) Deficiency and Sickle Cell Trait among Blood Donors in Nigeria." American Journal of Public Health Research, vol. 2, no. 2 (2014): 51-55. doi: 10.12691/ajphr-2-2-3.

\section{Introduction}

Blood donation from glucose-6-phosphate dehydrogenase (G6PD)-deficient and sickle cell trait (SCT) donors might alter the quality of the donated blood during processing, storage or in the recipient's circulatory system [18]. Blood donors are screened individuals that donate blood specifically to benefit a particular person (recipient) with the purpose of ensuring an adequate supply of blood when needed for accident victims, people needing surgery, people suffering from certain diseases and for medical research. The donor's blood are not routinely screened for G6PD deficiency in blood banks, because most common variants that cause acquired hemolytic anaemia pose little health hazards [4]. Intracorpuscular red blood cell (RBC) defects might affect its survival, resistance to various stresses and/or interaction with other cells like leukocytes or endothelial cells. It is of high significance if such red cells are to be donated and transfused to a recipient encountering a stressful event. Glucose-6-phosphate dehydrogenase (G6PD) deficiency is an X-linked enzymopathy characterized by inability of RBCs to counter balance oxidative stress, exposing them to intravascular haemolysis. Glucose-6-Phosphate dehydrogenase (G6PD) is a key enzyme of the pentose monophosphate pathway, and its deficiency is the most common inherited enzymopathy worldwide. Haemoglobin-S (Hb-S) is the most common haemoglobin variant, which is brought by an autosomal structural single-point mutation and characterized by poor solubility in the deoxygenated state followed by polymerization leading to RBC shape distortion, rigidity and extravascular haemolysis; among all inherited RBC disorders, G6PD deficiency and sickle cell trait (SCT) share the following features: being highly frequent in many geographical areas and ethnic groups; usually asymptomatic and in stable conditions not altering haemoglobin level, RBC count and indices, hence easily missed by routine complete blood count (CBC) and clinical history taken from a person who has not been screened for them or experienced any acute haemolytic attack. For these reasons, it is not uncommon to encounter persons who are affected by the same conditions as prospective blood donors. There are controversies 
regarding the quality of blood donated by these two groups during processing, storage or in the recipient's circulatory system. The use of G6PD-deficient blood has been studied for simple and exchange transfusions. It has been proposed that several biochemical changes and depletion in the antioxidant defense system occur on storage of G6PD-deficient blood [15,20]. In infants, Mimouni et al., described haemolysis in two preterm infants who received G6PD-deficient donor blood; neither infant received drugs known to be haemolytic, both infants required further intervention by exchange transfusions [17]. In the exchange transfusion practice with G6PD-deficient blood, a lesser drop in post-exchange total serum bilirubin, prolongation of the duration of phototherapy, the need for repeat exchange transfusions and occurrence of massive intravascular haemolysis in infants have also been reported [22,24]. The above complications have been reported in patients with normal G6PD activity. However, in high-prevalence areas of G6PD deficiency, more than $40 \%$ of neonates with jaundice that might require exchange transfusion are G6PD-deficient [7]; hence the incidence and severity of these complications are expected to be higher. The use of G6PD-deficient blood in adults did not show significant adverse clinical consequences following transfusion except biochemical changes reflecting mild haemolysis in one of the prospective studies $[14,16,25]$. This can be due to higher blood volume of the patient and the effect of the normal blood transfused along with the G6PD-deficient one if the patient received two units or more [1]. In Mediterranean and Middle East, the interaction between G6PD Mediterranean mutation and alpha-thalassemia can ameliorate the clinical complications; donor red blood cells from G6PD deficient donors have shortened life span and will not benefit the recipients. Sickle cell traits (SCT) have been considered as a benign condition. However, life-threatening complications may occur, and these clinical complications have been reported by several in vitro studies in which $\mathrm{Hb}$-AS red cells showed abnormality of their filterability [21]. RBCs collected from SCT donors frequently occlude WBCs' reduction filters. The main cause of this filtration failure is haemoglobin polymerization. There are many parameters that might further affect the adequacy of WBC filtration, including temperature, platelets, osmolarity, type of anticoagulant, time of storage and oxygen saturation of the blood unit $[8,9,26,27,28]$. Failure of adequate WBC reduction has been shown to increase the incidence of febrile non-haemolytic transfusion reaction, transmission of leukocyte-associated viruses and HLA alloimmunization [28]. Storage of Hb-AS whole blood in large-capacity oxygen-permeable bags increases oxygen tension and allows more effective WBC reduction by filtration [9,27]. The acute congestive crisis-like syndrome associated with $\mathrm{Hb}$-AS red cell exchange transfusion is rarely seen, mainly due to the modifying effect of a concurrent normal blood transfusion [1]. Transfusion with G6PD-deficient and sickle cell trait blood carries a potential risk of hemolytic complications in the recipient's circulatory system, this call for the attention of the relevant authority that blood donors should be adequately screened for G6PD deficient and sickle cell trait before such blood is transfused to avert its consequences on the recipients, hence the need for this study.

\section{Materials and Methods}

\subsection{Study Area}

Ekiti State is a state in southwest Nigeria, situated in the Northern part of old Ondo State and covers a land area of about 7,000 sq. kilometres. Its North-South extent boundary with Kogi State at Iye/Eruku and South boundary with Ikere/iju boundary along 5.30' E) is 88 Kilometres while the West-East extent borders Osun State at itawure/Ijebu-Jesa and East boundary with Omuo/Igasi along Latitude 7'70' N is 100 kilometres. Ekitiland which constitutes $52 \%(1,441,850)$ of the 1963 population of the old Ondo State $(2,747,121)$ consists of 16 Local Government Areas. This work was carried out in the Blood Bank and Hematology laboratory of Federal Medical Center, Ido Ekiti, Ekiti State.

\subsection{Samples Collection}

A total of 314 blood donor samples were collected for the study, the samples were collected from prospective and suitable blood donors after proper screening for donation.

\section{Methodology}

\subsection{Estimation of Glucose-6-Phosphate Dehydrogenase (G-6-Pd)}

Glucose-6-Phosphate dehydrogenase (G-6-PD) was determined using two standard methods; methaemoglobin reduction test and fluorescent spots test.

\subsubsection{Methaemoglobin Reduction Test}

Clean test tubes were arranged and labeled test, normal, and deficient. Into each of the tubes labeled test $0.05 \mathrm{ml}$ of sodium nitrite and $0.05 \mathrm{ml}$ of methylene blue reagents were dispensed. To the tubes labeled Deficient $0.05 \mathrm{ml}$ sodium nitrite only was dispensed and to those labeled normal were no reagent dispensed. $1.0 \mathrm{ml}$ of the blood sample was then dispensed into all the tubes and mixed after which they were corked with cotton wool and incubated at $37^{\circ} \mathrm{C}$ for $3 \mathrm{~h}$. At the end of the incubation, 3 clean test tube were arranged and labeled as before (test, normal, deficient), $10 \mathrm{ml}$ of distilled water was dispense into each of the tubes and $0.1 \mathrm{ml}$ of the respective incubated sample was transferred into each of the tubes accordingly and a colour comparation of the three was done [10].

\subsubsection{Fluorescent Spot Test}

Exactly $0.01 \mathrm{ml}$ of blood was added to $0.2 \mathrm{ml}$ of substrate and $0.01 \mathrm{ml}$ of the control (Deficient, intermediate and normal) was also added to the substrate separately. A drop of the mixture was transferred to its respective column on an absorbent paper at zero minutes and the remaining content was incubated at $37^{\circ} \mathrm{C}$. Also at 5 and 10 min a drop of the respective sample was again transferred to the absorbent paper and allowed to dry after which the spots were viewed using ultraviolet light [5].

\subsubsection{Haemoglobin Electrophoresis}


$0.3 \mathrm{ml}$ of blood sample was used to prepared hemolysate by centrifuge at $3000 \mathrm{~g}$ for ten minutes with Hittich universal bench centrifuge, model 1200. Plasma was aspirated off while the precipitate (blood cell layer) was resuspended in equal volume of normal saline $(0.85 \%$ $\mathrm{NaCl}$ ) for washing. The washing was repeated three times and finally resuspended in equal volume of normal saline. The red blood cell suspension (40 ul) was mixed with equal volume of distilled water to lyse the blood cell. The resulting haemoglobin lysate (the lysate) was used for haemoglobin genotype determination [29]. The method described by Brown was used for haemoglobin electrophoresis. A small quantity of hemolysate of venous blood from each of the subject was placed on a cellulose acetate membrane and carefully introduced into the electrophoretic tank containing tris-EDTA-borate buffer at $\mathrm{pH}$ 8.6. Electrophoretic separation was then allowed to operate for 15 to 20 minutes at an electromotive force (e. m. f) of 160 v. The results were read immediately. Hemolysate from blood samples of known haemoglobin (AA, AS, AC, SC, CC and SS) were run as controls.

\section{Result}

There was no difference in the results obtained using the two methods for G6PD assay. Out of the 314 blood donors, 81 (25.8\%), 169 (53.8\%) and 64 (20.4\%) were commercial blood donors, family replacement blood donors and voluntary blood donors respectively. 80 (25.5\%) of the blood donors were G6PD deficient while 234 (74.5\%) were G6PD normal, G6PD deficient among commercial blood donors, family replacement blood donors and voluntary blood donors were 40 (50.0\%), 28 (35.0\%) and 12 (15.0\%) respectively. Haemoglobin genotype AA, AS, AC and SC among blood donors were
210 (66.9\%), 82 (26.1\%), 21 (6.7\%) and 1 (0.3\%) respectively, 210 (66.9\%) were normal haemoglobin AA while 104 (33.1\%) were haemoglobin variants AS, AC and SC. Out of 104 haemoglobin variants AS, AC and SC had 82 (78.8\%), 21 (20.2\%) and 1 (1.0\%) respectively. Prevalence of G6PD deficient and haemoglobin variants among blood donors showed that; commercial blood donors had highest G6PD deficient with prevalence of 40 (50.0\%) and highest haemoglobin variants AS, AC and SC with prevalence of 31 (29.8\%), 10 (9.6\%) and 1 (1.0\%) respectively as compared to family replacement donors and voluntary donors as showed in Table 1. Haemoglobin variants AS, AC and SC among G6PD deficient were 31 (38.7\%), 5 (6.3\%) and 1 (1.3\%) respectively, blood group $\mathrm{O}$ rhesus D positive had highest G6PD deficient with prevalence of $51(63.7 \%)$ as showed in Table 2. Age group 25-34 had highest G6PD deficient prevalence of 34 (42.5\%) while age group 15-24 had highest haemoglobin variants AS, AC and SC with prevalence of 39 (26.9\%), $11(7.6 \%)$ and $1(0.7 \%)$ respectively. 247 (78.7\%) of the blood donors were males and 67 (21.3\%) were females; prevalence of G6PD deficient in sex distribution were 57 (71.3\%) and 23 (28.7\%) for males and females respectively while males had highest haemoglobin variants as compared to females as showed in Table 3 and Table 4. Age and sex distribution among blood donors showed that; family replacement donors had highest frequency of 169 (53.8\%), commercial donors and voluntary donors had 81 (25.8\%) and 64 (20.4\%) respectively. Age group 15-24 had highest number of donors with prevalence in family replacement donors. Sex distribution among blood donors with prevalence in family replacement donors were 125 (74.0\%) and 44 (26.0\%) in males and females respectively as in Table 5.

Table 1. revalence of g6pd deficient and haemoglobin variants among blood donors

\begin{tabular}{|c|c|c|c|c|c|c|}
\hline & \multicolumn{2}{|c|}{ G6PD STATUS HAEMOGLOBIN VARIANTS } \\
\hline BLOOD DONORS & NORMAL & DEFICIENT & AA & AS & AC & SC \\
\hline COMMERICAL & 41 & 40 & 39 & 31 & 10 & 1 \\
\hline DONORS & $(17.5 \%)$ & $(50.0 \%)$ & $(18.6 \%)$ & $(29.8 \%)$ & $(9.6 \%)$ & $(1.0 \%)$ \\
\hline RELATIVE & 141 & 28 & 13 & 29 & 7 & - \\
\hline REPLACEMENT & $(60.3 \%)$ & $(35.0 \%)$ & $(63.3 \%)$ & $(27.9 \%)$ & $(6.7 \%)$ & \\
\hline VOLUNTARY & 52 & 12 & 38 & 22 & 4 & - \\
\hline DONORS & $(22.2 \%)$ & $(15.0 \%)$ & $(18.1 \%)$ & $(21.2 \%)$ & $(3.8 \%)$ & \\
\hline
\end{tabular}

Table 2. prevalence of g6pd deficient among blood donor in haemoglobin variants and blood group

\begin{tabular}{|c|c|c|c|c|c|c|c|c|c|c|c|}
\hline & \multicolumn{4}{|c|}{ HAEMOGLOBIN VARIANTS } & \multicolumn{7}{|c|}{ BLOOD GROUPS } \\
\hline G6PD & AA & AS & AC & $\mathrm{SC}$ & APOS & BPOS & ABPOS & OPOS & ANEG & BNEG & ONEG \\
\hline \multirow{2}{*}{ NORMAL } & 167 & 51 & 16 & - & 30 & 42 & - & 142 & - & 1 & 19 \\
\hline & $(74.1 \%)$ & $(21.8 \%)$ & $(6.8 \%)$ & $(12.8 \%)$ & $(18.7 \%)$ & $(60.7 \%)$ & $(0.4 \%)$ & $(8.1 \%)$ & & & \\
\hline \multirow{2}{*}{ DEFICIENT } & 43 & 31 & 5 & 1 & 20 & 6 & 1 & 51 & 1 & _- & 1 \\
\hline & $(53.7 \%)$ & $(38.7 \%)$ & $(6.3 \%)$ & $(1.3 \%)$ & $(25.7 \%)$ & $(7.5 \%)$ & $(1.3 \%)$ & $(63.7 \%)$ & $(1.3 \%)$ & $(1.3 \%)$ & \\
\hline
\end{tabular}

Table 3. prevalence of g6pd deficient among donors in age and sex distribution

\begin{tabular}{|c|c|c|c|c|c|c|c|}
\hline & \multicolumn{3}{|c|}{ AGE GROUPS } & \multicolumn{3}{c|}{ SEX } \\
\hline G6PD & $15-24$ & $25-34$ & $35-44$ & $45-54$ & $55-64$ & MALE & FEMALE \\
\hline \multirow{2}{*}{ NORMAL } & 131 & 92 & 26 & 1 & 2 & 190 & 44 \\
\cline { 2 - 8 } & $(48.3 \%)$ & $(39.3 \%)$ & $(11.1 \%)$ & $(0.4 \%)$ & $(0.9 \%)$ & $(81.2 \%)$ & $(18.8 \%)$ \\
\hline \multirow{2}{*}{ DEFICIENT } & 32 & 34 & 10 & 3 & 1 & 57 & 23 \\
\cline { 2 - 8 } & $(40.0 \%)$ & $(42.5 \%)$ & $(12.5 \%)$ & $(3.7 \%)$ & $(1.3 \%)$ & $(71.3 \%)$ & $(28.7 \%)$ \\
\hline
\end{tabular}


Table 4. prevalence of haemoglobin variants among donors in age and sex distribution

\begin{tabular}{|c|c|c|c|c|c|c|c|}
\hline \multirow[b]{2}{*}{ HAEMOGLOBIN } & \multicolumn{5}{|c|}{ AGE GROUPS } & \multicolumn{2}{|c|}{ SEX } \\
\hline & $15-24$ & $25-34$ & $35-45$ & $45-54$ & $55-64$ & MALE & FEMALE \\
\hline \multicolumn{8}{|l|}{ VARIANTS } \\
\hline \multirow{2}{*}{ AA } & 95 & 84 & 27 & 1 & 3 & 158 & 52 \\
\hline & $(65.5 \%)$ & $(66.7 \%)$ & $(75.0 \%)$ & $(25.0 \%)$ & $(100 \%)$ & $(64.0 \%)$ & $(77.6 \%)$ \\
\hline \multirow{2}{*}{ AS } & 39 & 35 & 5 & 3 & - & 69 & 13 \\
\hline & $(26.9 \%)$ & (27.8\%) & $(13.9 \%)$ & $(75.0 \%)$ & & $(27.9 \%)$ & $(19.4 \%)$ \\
\hline \multirow{2}{*}{ AC } & 11 & 6 & 4 & 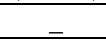 & - & 19 & 2 \\
\hline & $(7.6 \%)$ & $(4.8 \%)$ & $(11.1 \%)$ & & & $(7.7 \%)$ & $(3.0 \%)$ \\
\hline \multirow{2}{*}{ SC } & 1 & - & - & _ & - & 1 & - \\
\hline & $(0.7 \%)$ & & & & & & $(0.4 \%)$ \\
\hline
\end{tabular}

Table 5. age and sex distrubution among blood donors

\begin{tabular}{|c|c|c|c|c|c|c|c|}
\hline & \multicolumn{5}{|c|}{ AGE GROUPS } & \multicolumn{2}{|c|}{ SEX } \\
\hline BLOOD DONORS & $15-24$ & $25-34$ & $34-44$ & $45-54$ & $55-64$ & MALE & FEMALE \\
\hline COMMERCIAL & 43 & 26 & 10 & & 2 & 73 & 8 \\
\hline DONORS & $(53.1 \%)$ & $(32.1 \%)$ & $(12.3 \%)$ & $(2.5 \%)$ & (90.1\%) & $(9.9 \%)$ & \\
\hline FAMILY & 65 & 79 & 20 & 4 & 1 & 125 & 44 \\
\hline REPLACEMENT & $(38.5 \%)$ & $(46.7 \%)$ & $(11.8 \%)$ & $(2.4 \%)$ & $(0.6 \%)$ & $(74.0 \%)$ & $(26.0 \%)$ \\
\hline VOLUNTARY & 37 & 21 & 6 & _ & _ & 49 & 15 \\
\hline DONORS & $(57.8 \%)$ & $(32.8 \%)$ & $(9.4 \%)$ & & & $(76.6 \%)$ & $(23.4 \%)$ \\
\hline
\end{tabular}

\section{Discussion}

In this present study, 80 (25.5\%) of the blood donors were G6PD deficient; 40 (50.0\%), 28 (35.0\%) and 12 (15.0\%) of G6PD deficient blood donors were commercial blood donors, family replacement blood donors and voluntary blood donors respectively; prevalence of G6PD deficient in this present study was similar to what Bhagwat and Bapat reported, stated that out of 2680 blood donors screened for G6PD, 709 (26.45\%) were G6PD deficient. However, prevalence of G6PD deficient in this present study was higher compared to Akanni et al., 2010 who reported prevalence of G6PD deficiency in blood donors as $19.5 \%$ in Osogbo Osun State, Nigeria. Seyed et al., 2007 also reported that out of the 261 blood bags screened for G6PD deficiency, $14.17 \%$ were G6PD deficient. However, prevalence of G6PD deficiency in Africa is (1.2-30.7\%), about $19 \%$ of blood donors in Nigeria and 14\% in Iran, are G6PD deficient, Ivory Coast 30\%, Ghana 26\%, Burkina Faso 25\%, Gabon 22\%, America (1.3-9.7\%) Brazil, Colombie, USA (3.2\%) Mexico 1.3\%, Asia (3.1-28.5\%) Cambodia, Myanmar, Malaysia, Europe (0.2-11.9\%), Italy Greece Middle East (2-17\%) [19]. In this present study, 247 (78.7\%) of the blood donors were males and 67 (21.3\%) were females; prevalence of G6PD deficient in sex distribution were 57 (71.3\%) and 23 (28.7\%) for males and females respectively; this was lower compared to sex distribution in Akanni et al., 2010 showed that $89.7 \%$ of the deficient patients are males and $10.3 \%$ were females. The reason behind this fact is that the abnormal gene responsible for deficiency is located on the X-chromosome. Therefore, the illness associated with G6PD deficiency occurs more frequently in males than in females. G6PD deficiency is inherited from females who carry one copy of the gene on one of their $\mathrm{X}$ chromosome to half of their sons. Sons who receive the gene are G6PD deficient and daughters who do not receive the gene are unaffected [2]. The higher rate of male donors than females may be a result of their high packed cell volumes (PCV) which is usually higher than that of their female counterparts. The normal range for the male is between $40 \%$ and $54 \%$ and that of the females is between $36 \%$ and $46 \%$. Besides, higher hemoglobin values in males (normal range 13 - $18 \mathrm{~g} / \mathrm{dl}$ ) compared to females $(12-15 \mathrm{~g} / \mathrm{dl})$ or other screening criteria of the donors usually exclude the females from blood donation. Those females excluded are the lactating mothers, pregnant women and menstruating women [10]. Similarly, a study carried out in Shiraz, Southern Iran about the prevalence of G6PD deficiency among male donors established that $80 \%$ of the blood donors were male [4]. Age distribution in this present study showed that, age group 15-24 had highest number of blood donors with prevalence of 169 (53.8\%) in family replacement donors, this is similar to Gaga deep et al., 2010 who reported 55\% as replacement donors. Haemoglobin genotype AA, AS, AC and SC among blood donors with Prevalence of 210 (66.9\%), 82 (26.1\%), 21 (6.7\%) and 1 (0.3\%) respectively reported in this study is similar to Akhigbe et al., 2009 who reported that out of 1122 students, 71.03\%, 22.19\%, $5.26 \%$ and $0.80 \%$ were AA, AS, AC and SC respectively. Similarly, Erhabor et al., 2010 reported 69.1\% and 29.4\% for AA and AS respectively. Also, Esan et al., 2012 reported $72.8 \%$ and $23.5 \%$ for AA and AS respectively which is similar to this present study.

\section{Conclusion}

Transfusion with G6PD-deficient blood carries a potential risk of hemolytic complications, especially if it is used for exchanged blood transfusion in neonates. On the other hand, the blood donated from SCT donors, apart from its undesired effects if transfused to sickle cell disease patients, also leads to WBC filtration failure. For these reasons, in high-prevalence areas for SCT and/or G6PD deficiency, donation can be accepted but G6PDdeficient blood should be labeled and should not be released to transfuse a G6PD-deficient patient or to exchange in the pediatric age group, particularly neonates. On the other hand, SCT units need to be labeled too, and such blood is better stored in bags that allow increased $\mathrm{O}_{2}$ saturation and not used to transfuse sickle cell disease patients or in patients where WBC filtration is of great concern. In blood banks with limited resources where screening for SCT and G6PD deficiency is not feasible, we advise to screen the units that are likely to be transfused to high-risk recipients, particularly if singleunit transfusion is going to be undertaken.

\section{Recommendation}


We recommend that all units of blood should be screen for G6PD deficiency and sickle cell trait and to defer donations from donors with either of these conditions, unless if needed for special blood group compatibility, platelet apheresis or if these are likely to affect the blood bank inventory. If such blood is to be used, special precautions need to be undertaken to avoid complications in high-risk recipients. Also, commercial blood donors should be discouraged from blood donation due to high risk involved, voluntary and family replacement blood donors should be greatly encouraged to improve quality and safety of blood donation.

\section{References}

[1] Ahmed MA, Al-Ali AK, Al-Idrissi HY, Al-Sibai MH, Al-Mutairy AR, Knox-Macaulay H (1991). Sickle cell trait and G6PD deficiency in blood donors in eastern Saudi Arabia. Vox Sang; 61: 69-70.

[2] Akanni1 E.O, Oseni1 B.S.A, Agbona V.O, Tijani B.A, Tosan E, Fakunle E.E and Mabayoje V.O (2010). Glucose-6-phosphate dehydrogenase deficiency in blood donors and jaundiced neonates in Osogbo, Nigeria; Journal of Medical Laboratory and Diagnosis; Vol. 1 (1) pp. 1-4.

[3] Akhigbe R.E, Ige S.F, Afolabi A.O, Azeez O.M, Adegunlola G.J and Gamidele J.O (2009). Prevalence of haemoglobin variants, $\mathrm{ABO}$ and rhesus blood group in Ladoke Akintola University of Technology, Ogbomoso, Nigeria. Trends in Medical Research, Academic Journals Inc; 1819-3587.

[4] Amoozegar HM, Mirshakeris, Paishva N (2005). Prevalence of Glucose- 6-Phosphate Dehydrogenase Deficiency among male donors in Shiraz, Southern Iran. Iran J. Med. Sci. 30 (2): 94-96.

[5] Beutler E, Mitchel M (1968). Special Modification of the Fluorescent Screening method for Glucose-6-phosphate dehydrogenase deficiency Blood pp. 32: 816.

[6] Bhagwat G.P, Bapat J.P (1987). Glucose 6-phosphate dehydrogenase deficiency in Bahraini blood donors; Bahraini medical bulletin, Vol. 9; No 3: 120-122.

[7] Bienzle U, Effiong C, Luzzatto L (2008). Erythrocyte glucose 6phosphate dehydrogenase deficiency (G6PD type A-) and neonatal jaundice. Acta Paediatr; 65701: 3.

[8] Brandão MM, Saad ST, Cezar CL, Fontes A, Costa FF, BarjasCastro ML (2003). Elastic properties of stored red blood cells from sickle trait donor units. Vox Sang.; 85: 213-215. Byrne KM, Leitman SF, Schechter AN, Stroncek DF (2003). Increasing oxygen tension.

[9] Improves filtration of sickle trait donor blood. Br J Haematol; 122: 678-681.

[10] Cheesbrough M (2002). Blood Transfusion Practice: Blood donation and Storage of blood, District Laboratory Practice in tropical countries, low-price edition by Cambridge Universal Press pp. 352-353.

[11] Erhabor O, Adias T.C, Jeremiah Z.A, Hart M.L (2010). Abnormal haemoglobin variants, ABO and rhesus blood group distribution among students in the Niger Delta of Nigeria. Pathology laboratory medicine international; 2: 41-46

[12] Esan A.J, Omisakin C.T, Okhuakhua O (2012). Frequency distribution of haemoglobin variants, $\mathrm{ABO}$ and rhesus blood groups among children in Ido-Osi Local Government, Ekiti State, Nigeria. Journal of medical laboratory science; vol. 12, No 2: 1018.

[13] Gagandeep Kaur, Sabita Basu, Ravneet Kaur, Paramjit Kaur, Shailja Garg (2010). Patterns of infections among blood donors in a tertiary care centre: a retrospective study. The national medical journal of India vol. 23; No 3: 147-149.

[14] Huang CS, Sung YC, Huang MJ, Yang CS, Shei WS, Tang TK (1998). Content of reduced glutathione and consequences in recipients of glucose-6-phosphate dehydrogenase deficient red blood cells. Am J Hematol.; 57: 187-192.

[15] Józwik M, Szczypka M, Gajewska J, Laskowska-Klita T (1997). Antioxidant defence of red blood cells and plasma in stored human blood. Clin Chim Acta.; 267: 129-142.

[16] McCurdy PR, Morse EE (1975). Glucose-6-phosphate dehydrogenase deficiency and blood transfusion. Vox Sang. 28: 230-237.

[17] Mimouni F, Shohat S, Reisner SH (1986). G6PD-deficient donor blood as a cause of hemolysis in two preterm infants. Isr J Med Sci.; 22: 120-122.

[18] Mohammed K Alabdulaai, Khaled M Alayed, Abdulazizi F Alshakh, Shihab A Almashhadani (2010). Prevalence of glucose6-phosphate dehydrogenase deficiency and sickle cell trait among blood donors in Riyadh. Asian journal of transfusion science. 4 (1): 31-33.

[19] Kamran Moradkhani (2011). Clinical heterogeneity of G6PD deficiency: New variants and Correlation between genotype and phenotype, results of a five-year-survey; CHU Henri Mondor Creteil Dorys 2011 Strasbourg

[20] Orlina A R, Josephson A M, McDonald BJ (1970). The poststorage viability of glucose-6-phosphatase dehydrogenasedeficient erythrocytes. J Lab Clin Med.; 75: 930-936.

[21] Ould Amar AK (2006). Red blood cells from donors with sickle cell trait: A safety issue for transfusion? Transfus Med.; 16: 248253.

[22] Sandip S, Praveen K, Sai SK, Gurjeewan G, Anil N (2009). Donor blood glucose 6-phosphate dehydrogenase deficiency reduces the efficacy of exchange transfusion in neonatal hyperbilirubinemia. Pediatrics; 123: 96-100.

[23] Seyed HN, Amir AV (2007). The Prevalence of G6PD deficiency in blood transfusion recipent. Haematology 12: 85-88.

[24] Shahriary M, Pishva N, Mohammadi T (1997). Incidence of G6PD deficiency in Fars province. Iran J Med Sci.; 22: 151.

[25] Shalev O, Manny N, Sharon R (1993). Post-transfusional hemolysis in recipients of glucose-6-phosphate dehydrogenasedeficient erythrocytes. Vox Sang.; 64: 94-98.

[26] Stroncek DF, Rainer T, Sharon V, Byrne KM, Noguchi CT, Klein HG, et al., 2002 Sickle Hb polymerization in RBC components from donors with sickle cell trait prevents effective WBC reduction by filtration. Transfusion; 42: 1466-1472.

[27] Stroncek DF, Byrne KM, Noguchi CT, Schechter AN, Leitman SF (2004). Increasing hemoglobin oxygen saturation levels in sickle trait donor whole blood prevents hemoglobin $\mathrm{S}$ polymerization and allows effective white blood cell reduction by filtration. Transfusion; 44: 1293-1229.

[28] Schuetz AN, Hillyer KL, Roback JD, Hillyer CD (2004). Leukoreduction filtration of blood with sickle cell trait. Transfus Med Rev.; 18: 168-176.

[29] Uzoegwu P.N and Onwurah A.E 2003. Prevalence of heamoglobinopathy and malaria disease in the population of old Aguata Division, Anambra State, Nigeria. Biokemistri, 15: 57-66. 